\title{
JURNAL TAHAPAN KELOLA \\ MANAJEMEN SEKOLAH
}

\section{Feny Veronikasari}

\author{
Universitas Nahdlatul Ulama Sidoarjo
}

\section{Pengantar}

Anda seorang kepala sekolah atau wirausahawan pendidikan yang ingin belajar?. Salah satu cara terbaik di mana Anda berproses dengan sistem manajemen sekolah yang lebih baik di sekolah Anda adalah dengan mendirikan komunitas pembelajaran profesional. Sudah menjadi rahasia umum bahwa pengembangan profesional konvensional bisa menjadi urusan yang agak mahal. Ada begitu banyak biaya untuk mengurus di sini seperti biaya yang harus dibayarkan kepada pembicara, mempekerjakan guru pengganti untuk menutupi kelas, dan biaya yang harus dikeluarkan untuk teks. Para ahli juga mengatakan bahwa model pengembangan profesional saat ini - dengan beberapa pertemuan dan lokakarya bertebaran di sana-sini - juga tidak selalu menghasilkan hasil yang diinginkan. Berikut beberapa langkah agar Anda sukses dan 
memastikan bisnis pendidikan dan sekolah Anda pimpin dapat berhasil.

\section{Mendelegasikan}

Pemimpin cenderung ulet, pekerja keras, dan pintar. Tetapi itu tidak berarti seorang pemimpin harus melakukan semuanya sendiri. Melimpahkan. Meminta bantuan. Anda akan hidup jauh lebih lama dan lebih bahagia jika melakukannya (Bauer, 2019).

\section{Komunitas Belajar Profesional}

Membangun komunitas belajar profesional di sekolah Anda dan selalu menjadi model pembelajaran. Meneliti praktik terbaik untuk pengajaran dan pembelajaran abad 21 dan memastikan sekolah memiliki rencana pengembangan profesional untuk guru dan orang tua. Pengajaran yang berkualitas adalah cara terbaik untuk meningkatkan pembelajaran siswa, jadi bantu guru Anda menjadi yang terbaik (Driscoll, 2018). Pendidikan Indonesia membutuhkan peningkatan akses, mutu dan relevansi pendidikan untuk memberi manfaat membangun bagi pendidikan dan rakyat Indonesia (Irawan et al., 2018).

\section{Menjadi Rentan}

Saya menulis posting tentang ini yang disebut "Lepaskan Topeng." Kerentanan mengarah pada keaslian dan kepercayaan. Ketika Anda memiliki 
kepercayaan, tidak ada yang bisa Anda capai (Bauer, 2019).

\section{Jaga Pelajar Anda Terlibat}

Semakin banyak siswa terlibat dalam kegiatan, semakin sedikit mereka menyebabkan masalah. Pastikan Anda memberikan kelas interaktif dan mengajar siswa dengan penuh semangat. Lebih baik melibatkan siswa dari sekadar memberi kuliah. Oleh karena itu akan disarankan untuk membuat siswa menulis sambil mengajar (Edsys, 2016).

\section{Terhubung dengan Kepala Sekolah Lainnya}

Cari tahu apa yang mereka lakukan di sekolah mereka. Lihat apa yang bisa dan tidak berfungsi untuk mereka dan buat solusi bersama (Drewitt, 2017).

\section{Cinta Robbi}

Relevansi pendidikan antara guru dan murid itu seperti aliran listrik dengan lampu. Bagaimana lampu itu bisa menyala kalau aliran listriknya juga mati ?. Bagaimana murid itu bisa berprestasi sedangkan guru sendiri tidak pernah berprestasi dan mendoakan (Fidiana, Istiana, Rosyidah, \& Purnomo, 2017). Setiap manusia hamba Tuhan yang memiliki ilmu selayaknya harus mengamalkan ilmu tersebut (Asitah, Usmawati, Rosyidah, \& Purnomo, 2017). Pendidikan adalah kunci untuk membuka pintu emas kesuksesan. Wirausaha pendidikan dengan motivasi bisnis dengan Allah Ta'ala sebagai bentuk kenyamanan untuk 
ibadah. Tips mengelola institusi pendidikan adalah niat mendidik dan berjuang karena Allah ta'ala. Niscaya rintangan sebesar apapun akan terasa ringan dihadapan kita. Melihat anak mengenal Allah Ta'ala dan sukses akhlak dan pengetahuannya merupakan kebahagiaan pendidik (Yuniarti, Kautsari, Sholichah, Purnomo, \& Rosyidah, 2017). Prinsip pendidikan adalah sosial. Sebagai seorang guru, kita harus memiliki kepedulian sosial (Asitah et al., 2017). Guru harus bisa membangun generasi muda untuk masa depan. Hiduplah untuk mengamalkan ilmu (Sholichah, Istiqomah, Rosyidah, \& Purnomo, 2017).

\section{Jadilah Forthright}

Siswa perlu memahami apa yang diketahui dan apa yang diminta untuk memiliki kemampuan menjawab (Suci et al., 2018). Forthright dan candid adalah kata-kata yang lebih baik daripada jujur karena, tentu saja, Anda tidak pernah ingin menjadi tidak jujur. Kami berbicara tentang selalu memberi tahu guru, orang tua, dan warga distrik sekolah tentang kebenaran sekolah. Jika Anda membutuhkan lebih banyak uang untuk mencapai visi Anda, beri tahu komunitas pilihan yang Anda miliki. Anda mungkin perlu memotong sebagian anggaran secara substansial atau menaikkan pajak. Jika kinerja siswa mengalami kemunduran, jujurlah tentang hal ini dan mencari solusi. Jika keputusan sebelumnya salah, akui kesalahan Anda. Para pemimpin besar bertanggung jawab atas 
kesalahan dan berita buruk (Watanabe-Crockett, 2018).

\section{Pengusaha}

Bekerja sama, bertanggungjawab, dan amanah adalah prinsip wirausaha pendidikan (Nahdiyah, Amrina, Purnomo, \& Rosyidah, 2017). Edupreneur atau educational entrepreneur berasal dari dua kata yaitu education bermakna pendidikan dan entrepreneur bermakna pengusaha atau wirausahawan. Ada juga yang menyamakan istilah edupreneur dengan istilah teacherpreneur (Purnomo, 2017). Menjaga hubungan baik dengan wali siswa melalui melaksanakan janji dan pelayanan yang baik adalah bagian dari promosi wirausaha (Asitah et al., 2017).

\section{Merangkul Teknologi}

Sadarilah bahwa ia ada di sini untuk tinggal ... sekarang pelajari cara menjadi pemimpin di dalamnya (Drewitt, 2017). Guru merupakan seorang pendidik dan pengajar sekaligus sebagai pembentuk kepribadian siswa yang unggul, berwawasan dan baik (Maula et al., 2018). Cara memimpin sekolah adalah senantiasa musyawarah serta sharing bersama para guru atau dengan siapapun dan tetap mendekat pada Allah SWT (Yuniarti et al., 2017).

\section{Buat dan Terapkan Kebijakan Proaktif}

Setiap kepala sekolah harus menjadi penulis kebijakan yang mahir. Setiap sekolah berbeda dan 
memiliki kebutuhan unik mereka sendiri dalam hal kebijakan. Kebijakan berfungsi paling baik ketika ditulis dan diberlakukan sedemikian rupa sehingga sangat sedikit yang ingin mengambil kesempatan untuk menerima konsekuensi yang terlampir. Sebagian besar kepala sekolah akan menghabiskan sebagian besar hari mereka berurusan dengan disiplin siswa. Kebijakan harus dilihat sebagai pencegah gangguan yang mengganggu pembelajaran. Kepala sekolah yang berhasil adalah proaktif dalam pendekatan mereka terhadap penulisan kebijakan dan disiplin siswa. Mereka mengenali potensi masalah dan mengatasinya sebelum menjadi masalah yang signifikan (Meador, 2019).

\section{Tetap Beri Tahu Kantor Pusat}

"Pusat kota" bisa menjadi sekutu atau kritik Anda, jadi pastikan untuk meminta saran dan biarkan mereka tahu kisah perjalanan Anda di sepanjang jalan (Drewitt, 2017). Pemimpin sekolah dan wirausaha pendidikan seharusnya senantiasa menikmati proses karena tidak ada hal yang besar yang tidak dilakukan dari hal yang kecil. Semua butuh proses, karena kesuksesan tidak datang secara langsung tanpa berproses (Maula, Mufidah, Rosyidah, \& Purnomo, 2017). Komunikasi yang baik dengan masyarakat sekitar adalah kunci untuk dapat mengatasi masalah dan bisa bangkit dari keterpurukan manajemen 
pendidikan. Prinsip utama dan kepemimpinan wirausaha pendidikan adalah disiplin, kreatif, cerdas dan ulet (Qori'ah, Sholichah, Purnomo, \& Rosyidah, 2017).

\section{Noktah Pendidikan}

Pendidikan itu sebuah perhiasan dalam kemakmuran dan tempat bernaung dalam kesengsaraan (Maula et al., 2017). Guru merupakan seorang yag memilki tugas mulia sebagai pendidik dan pengajar sekaligus sebagai pembentuk kepribadian siswa (Maula et al., 2018). Cari ilmu yang bermanfaat dan patuhi aturan-aturan yang ada. Bijaksana dan pantang menyerah dalam belajar adalah kunci kesuksesan. Pendidikan adalah pelajaran yang harus kita pelajari setiap hari baik dari buku, lingkungan, teman, maupun keluarga agar kita tidak tertinggal (Qori'ah et al., 2017). Hasil penelitian menunjukkan bahwa penerapan pembelajaran dapat meningkatkan prestasi siswa (Iskandar, Rizal, Kurniasih, Sutiksno, \& Purnomo, 2018).

\section{Menerapkan Perubahan Sekolah yang Efisien}

Mulailah proses Anda sendiri untuk memaksimalkan upaya terfokus dan efektif di sekolah atau daerah Anda. Itu harus dimulai dengan pencarian yang jujur untuk menentukan prioritas berdasarkan bukti terbaik yang tersedia. Ini harus lebih dari 
"berbasis penelitian." Jika kita menghargai waktu dan logika, kita berutang kepada siswa untuk mencari dan menerapkan hanya apa yang bukti buktikan sebagai tindakan dan inisiatif paling efektif yang dapat kita temukan. Penentuan kritis ini harus diikuti oleh kampanye pengulangan yang sangat terfokus dan tidak malu-malu; ulasan; dan berlatih. Penguasaan dan implementasi yang konsisten — bukan sekadar paparan atau pelatihan - harus menjadi tujuan baru kami (Communicator, 2017).

\section{Menjaga Komunikasi yang Baik Dengan Guru}

Pemimpin sekolah sebisanya tegas, toleran terhadap bawahannya dan mengayomi. Pendidikan adalah catatan masa lalu dan pengajaran masa kini untuk masa depan bangsa (Fidiana et al., 2017). Membangun komunikasi sejak dini dan menjaganya sepanjang tahun. Tanyakan kepada guru apa sistem organisasi yang mereka gunakan. Bersedia untuk memeriksa, menandatangani, dan mengembalikan lembar perencana atau pekerjaan rumah. Tanyakan kepada guru berapa lama tugas yang harus diambil, dan berikan umpan balik tentang berapa lama tugas itu sebenarnya (Springer, 2019). 


\section{Memerlukan Siswa untuk Membersihkan Meja Mereka}

Siswa harus diminta untuk menyimpan hanya barang-barang yang diperlukan di atas meja. Ketika meja dibersihkan, guru akan bisa tahu persis tentang kegiatan yang dilakukan oleh siswa mereka. Guru akan memiliki kontrol yang lebih baik terhadap siswa (Edsys, 2016). Manajemen sekolah dilakukan dengan menerapkan standar kualitas dalam rekrutmen pengajar yaitu kedekatannya dengan amaliyah (Munjidah, Zannah, Purnomo, \& Rosyidah, 2017).

\section{Komunikasi yang Efektif}

Panduan berisi saran untuk mengelola segudang komunikasi sehari-hari yang melibatkan Anda sebagai kepala sekolah (Educational Leaders, 2019). Tips kelola sekolah adalah senantiasa belajar dan bekerja keras. Bersabarlah dengan masalah, sesungguhnya didalam kesulitan ada kemudahan (Sholichah et al., 2017). 


\section{References}

Asitah, N., Usmawati, D. Z., Rosyidah, E., \& Purnomo, A. (2017). MI Hasyim Asy'ari Ilmu Harus Terus Mengarus. In Wirausaha Pendidikan Indonesia (Jilid 2). Sidoarjo: UNUSIDA Press.

Bauer, D. (2019). 200 Tips for Effective School Leaders.

Retrieved June 14, 2019, from

https://www.betterleadersbetterschools.com/200-tipseffective-school-leaders/

Communicator. (2017). 4 Time Management Tips for Principals. National Association of Elementary School Principals, 40. Retrieved from https://www.naesp.org/communicator-june-2017/4time-management-tips-principals

Drewitt, P. (2017). 25 tips for School Principals. Retrieved June 13, 2019, from

https://www.linkedin.com/pulse/25-tips-schoolprincipals-paul-drewitt

Driscoll, M. (2018). 16 Success Tips for New 21st Century Principals. Retrieved June 23, 2019, from https://thinkstrategicforschools.com/16-success-tipsnew-21st-century-principals/

Edsys. (2016). 10 Awesome Tips to Manage School

Discipline Issues. Retrieved June 30, 2019, from https://www.edsys.in/10-awesome-tips-to-manageschool-discipline-issues/

Educational Leaders. (2019). Guides for managing your school. Retrieved June 29, 2019, from http://www.educationalleaders.govt.nz/Managingyour-school/Guides-for-managing-your-school

Fidiana, W., Istiana, Z., Rosyidah, E., \& Purnomo, A. (2017). MINU Waru 2 Insan Berkilau Cahaya Manfaat. In Wirausaha Pendidikan Indonesia (Jilid 4). Sidoarjo: UNUSIDA Press. 
Irawan, D. E., Purnomo, A., Sutiksno, D. U., Abraham, J., Alamsyah, A., Saputra, D. H., ... Rosyidah, E. (2018). Kajian Pendidikan Tinggi IDRI untuk DPR RI dan Ristek Dikti 2018. Bandung: ITB Press.

Iskandar, A., Rizal, M., Kurniasih, N., Sutiksno, D. U., \& Purnomo, A. (2018). The Effects of Multimedia Learning on Students Achievement in Terms of Cognitive Test Results. Journal of Physics:

Conference Series, 1114(1), 012019. https://doi.org/10.1088/1742-6596/1114/1/012019

Maula, I., Asitah, N., Munjidah, A., Nahdiyah, K., Yuniarti, D., Sholichah, S. A., ... Qori'ah, S. (2018). Kontribusi Kreativitas Guru SD dalam Induksi Pembelajaran. https://doi.org/http://doi.org/10.17605/OSF.IO/BS79 5

Maula, I., Mufidah, F. I., Rosyidah, E., \& Purnomo, A. (2017). SD Antawirya Islamic Javanese School Mother is Culture. In Wirausaha Pendidikan Indonesia (Jilid 1). Sidoarjo: UNUSIDA Press. Meador, D. (2019). 10 Things a Successful School Principal Does Differently. Retrieved June 28, 2019, from https://www.thoughtco.com/things-asuccessful-school-principal-does-differently-3194532 Munjidah, A., Zannah, I. P. N., Purnomo, A., \& Rosyidah, E. (2017). MI Thoriqussalam Berpegang Kepada Rosul. In Wirausaha Pendidikan Indonesia (Jilid 4). Sidoarjo: UNUSIDA Press.

Nahdiyah, K., Amrina, S., Purnomo, A., \& Rosyidah, E. (2017). SD Taman Pendidikan Islam Porong Iman Kuat Bekal di Akhirat. In Wirausaha Pendidikan Indonesia (Jilid 2). Sidoarjo: UNUSIDA Press. Purnomo, A. (2017). Pengertian Edupreneur. https://doi.org/10.31227/osf.io/8fnu6 
Qori'ah, S., Sholichah, S. A., Purnomo, A., \& Rosyidah, E. (2017). Progresif Bumi Sholawat dengan Kebenaran Semua Pasti Ada Jalan. In Wirausaha Pendidikan Indonesia (Jilid 3). Sidoarjo: UNUSIDA Press.

Sholichah, S. A., Istiqomah, A., Rosyidah, E., \& Purnomo, A. (2017). MI Darun Najah Berfikir Berkarya Berdzikir. In Wirausaha Pendidikan Indonesia (Jilid 3). Sidoarjo: UNUSIDA Press.

Springer. (2019). Tips for Managing Organization.

Retrieved July 1, 2019, from https://www.springerld.org/springer-experience/center/parentprograms/tips-organization

Suci, S. H. A., Rosyidah, E., Asitah, N., Aini, N., Murni, A. W., Anam, F., ... Kuraesin, A. D. (2018).

Learning from Picture and Picture Action Research : Enhancement of Counting Ability on Division of Numbers for Primary School Students. Journal of Physics: Conference Series, 1114(1), 012044. https://doi.org/10.1088/1742-6596/1114/1/012044 Watanabe-Crockett, L. (2018). The 10 School Leadership Best Practices That Make a Difference. Retrieved June 23, 2019, from https://www.wabisabilearning.com/blog/10-schoolleadership-best-practices

Yuniarti, D., Kautsari, M. F., Sholichah, F., Purnomo, A., \& Rosyidah, E. (2017). SMP SMA Al-Amin Ponpes Bahrul Hidayah Serahkan pada Allah Ta'ala. In Wirausaha Pendidikan Indonesia (Jilid 1). Sidoarjo: UNUSIDA Press. 